\title{
Nosography of the Psychopathological Disorders Among the Elements of the Cameroonian Defense Forces Wounded of War
}

\author{
Mbangmou Romuald Stone ${ }^{1 *}$ and Kaldadak Koufagued Martin ${ }^{2}$ \\ ${ }^{1}$ Department of Psychology, University of Yaounde1, Cameroon \\ ${ }^{2}$ Military Hospital of Yaounde, Cameroon \\ *Corresponding Author: Mbangmou Romuald Stone, Department of Psychology, \\ University of Yaounde1, Cameroon.
}

Received: February 27, 2020

Published: March 06, 2020

(C) All rights are reserved by Mbangmou

Romuald Stone and Kaldadak Koufagued Martin.

\begin{abstract}
This research attempts to describe and quantify the different psychopathological semiology's found among the war blessings within the Cameroonian defense forces. This makes it possible to appreciate the similarities and differences between this population and international statistics. From the interview, the evaluation questionnaires and the impairment tests, we made the grouped and quantified diagnoses to the various syndromes and problems encountered in the blessed soldiers of the war against the Cameroonian defense forces. These figures could serve as a basis for a subsequent epidemiological study on a larger population.
\end{abstract}

Keywords: War Trauma; Mental Disorders; Epidemiology; Cameroonian Army; Descriptive Study

\section{Introduction}

Since the beginning of the border war between the Cameroonian army and the Nigerian army in the Bakassi area dating back to the end of the 1980s [1], Cameroon's defense forces are increasingly facing crisis situations. After a period of crisis confronting the armed forces with the road cutters raging on the country's national elite, Boko-Haram has appeared since the end of 2012, bringing with it a new traumatic phenomenon: the attack by kamikaze. At the same time, the elements of the defensive forces must rescue the neighboring countries in crisis, like the Central African Republic, and others. These situations require the military to tap into their deep resources, develop high levels of resilience, and, where appropriate, deal with physical and / or mental suffering, which can lead to severe disability upon return from operations. These handicaps and postoperative suffering, require the expertise and intervention of two health professionals, namely doctors and clinical psychologists.

The clinical psychologist and the psychiatrist of the armies, because of their belonging to the military, are brought to exercise their arts in the most diverse conditions, whether in the framework of recruitments, training, care, prevention, or assistance to civilian populations. Formation units, intervention units, and hospital environments are the usual places of their activities. It is not uncommon for this practice to occur also in conflict situations in hostile environments, insecurity or isolation. The pathologies that these specialists encounter can take on a singular expression, making their missions more difficult, in the face of new situations, perhaps hitherto unknown [2]. With time, the repetitions of these singular experiences give these specialists a professional wealth from the point of view of the culture and the organization of their defense system. This is the axis under which we relied to initiate this study, after exactly 4 years of interventions in the field of psychic care among the Cameroonian soldiers, wounded of war, in medical evacuation at the military hospital region No. 1 of Yaounde, where we practice as a psychologist since August 06, 2013.

After four years of confrontation between the Cameroonian defense forces and the terrorist group called Boko Haram in the north of the country and more than a year of fighting against the seces- 
sionists, despite the repeated victories of the Cameroonian army, several categories of losses can be listed on his side. These may include loss of life (soldiers fallen on the front or back of the front), material and financial losses, loss of social balance, and especially the imbalance in the state of health of the elements of the forces defense and civilian citizens, an imbalance characterized by physical or psychological dysfunctions. In September 2017, three categories of population are received in the psychology and psychiatry department of the No. 1 military hospital in Yaoundé. These are civilian victims, their families and relatives (especially spouses and children), and elements of the Cameroon Defense Forces. As for the victims on the side of the Cameroon Defense Forces received in the service, they can be grouped into 3 categories according to the nature of the main reason for evacuation, namely: - physical wounds; psychic-wounded; - wounded both physically and psychically. We group these war victims under the concept of "survivors". The objective of this study is to describe the psychopathological semiology and to present an objective nosography of psychiatric pathologies within the Cameroonian defense forces. It is not a question of giving statistics on the wounded within this defense force, but of giving statistics on the different psychopathologies encountered within this population. This is necessary because, from the emic point of view, the conceptions as well as the manifestations of mental illnesses and the therapeutic route of patients vary from one culture to another.

The military, in the broadest sense of the term, is the professional most exposed to situations endangering his existence $[3,4]$. In 2014, in the space of a few months in Canada, "a dozen soldiers have ended their days" [3,4].These were soldiers returning from Afghanistan. According to a study published in June 2013 in the Canadian Journal of Psychiatry, more than $10 \%$ of soldiers serving in Afghanistan returned to Canada with mental health problems. Minor depression symptoms were observed in $3.3 \%$ of 16,193 subjects, major depressive disorder in $3.2 \%$ and post-traumatic stress disorder in $2.8 \%$ [5]. After 8 years, the number of soldiers with mental disorders has increased from $10 \%$ to $20 \%$ [6]. Following the withdrawal of troops in Afghanistan, the Canadian government has initiated a significant increase in financial resources for mental health, clinical and technological advances [4]. The French army insists on the psychological follow-up of the families of the soldiers well before the departure of these, during their mission, and on the return of the soldiers and, it created 4 new cells of medico-psy- chological emergencies, only one month after the attacks in Paris in December 2015 [7]. In the United States, a psychologist follows fewer than 10 soldiers in a year. These two examples allow us to enter the particular case of the Cameroonian defense forces, asking us about the place of the clinical psychologist and the psychiatrist in this defensive group, in this month of June 2016. The observation focused exclusively on these war wounded in medical evacuation at the military hospital region No. 1 (HMR1) of Yaoundé, allowed us to note the physical, psychological and relational difficulties. We question here the psychopathological profile of the Cameroonian soldier? As we have already pointed out above, the aim of this study is to explore the psychopathological semiology and the relationship failures of Cameroonian soldiers in general, and wounded war soldiers in medical evacuation at HMR1 in Yaounde in particular, is the goal of this study. In other words, it is a question of assessing the situation of the wounded soldier of war in medical evacuation at the HMR1 of Yaounde. This assessment has 4 evaluative dimensions, objectified by the questionnaire: Physical or physiological difficulties (physical impairment), psychological difficulties (mental disorder), relationship difficulties (conflict and social link).

\section{Materials and Methods}

Population

Data collection was made from elements of the Cameroon Defense Forces, wounded in war in medical evacuation at the No. 1 Military Hospital of Yaoundé. a group of elements of the Cameroonian armed forces, victims of physical and or psychological injury, were assessed, with an average age of 27.2 years.

Data collection method

Survey

66 semi-directive questionnaires were shared, 46 were retrieved.

Interview and tests (psychiatric counseling and psychological, and psychological assessments).

The individual interviews were conducted with the patient soldiers whose answers directly referred to the expression of a mental disorder, or deep relational, in order to complete the data of the questionnaire deemed very general.

During these interviews, several psychological and neuropsychological tests were passed to the patients. Several aspects of the functioning were evaluated: personality, and cognitive functions, psychopathology. These include the following tests and scales: 
- $\quad$ Mini mental status ([MMS], global assessment of cognitive functions)

- $\quad$ Rapid battery of frontal efficiency ([BREF], evaluation of the executive functions).

- Hamilton Depression Scale ([HDRs], Assessment and Followup of Anxiety Depressive Syndrome).

- Hospitality anxiety and depression scale ([HADs], diagnosis of anxiety and depression).

- $\quad$ PCL-S (Scale of Diagnosis and Assessment of Post-Traumatic Stress Disorder).

Note that it was not all these tests that we passed to each of the participants. The choice of the test was a function of the semiology presented by the soldier (diagnostic impression).

\section{Results}

The results presented in this section are those from the 46 questionnaires collected, so for a total of 46 patient soldiers. The oldest injuries date back to May 16, 2014. These results were associated with data from their medical records (anamnesis).

\section{Physical sphere}

Physical Injury: 97.82\% of patients, decreasingly distributed on lower limbs (53\%), upper limbs, torso, and head.

- $\quad 91.3 \%$ of the wounded required hospitalization, with a minimum duration of 2 weeks, a maximum duration of 2 years and a month, and an average hospital stay of 7 months and 2 weeks each.

- $72 \%$ of the wounded required surgery, with an average of 1.85 surgical operations in the operated patient population. $52 \%$ of the interventions were performed under general anesthesia.

- $\quad 6.5 \%$ claim to have recovered their pre-trauma ability.

- $\quad$ About $80 \%$ have a physical disability.

\section{Psychic sphere}

- $\quad 73.9 \%$ of the wounded have mood disorders (Dysthymia), with a prevalence of irritability $67.3 \%$, and other floating feelings: Fear / anxiety / worry, regret, anger, love, shame, regret, sadness, shame. The most floating disorder here is depression.
- $63 \%$ say they have changed their behavior in the negative direction. With predominant negative behaviors (behavioral disorders): Isolation and social phobia (58.6\%), Alcohol and other psychotropic drugs (47\%), does not support noises, memory disorder type anterograde amnesia (45.6\%).

- $52 \%$ exhibit avoidance behaviors such as noise, sleep, blood sight, violence, cars, and / or the military uniform view (Phobias).

- $\quad 28.9 \%$ have logorrhea, and 39\% have auditory and / or visual hallucinations characteristic of psychosis (Logorrhea and hallucinations are predictors of impending psychotic upheaval, if not yet expressive).

- $\quad 63.6 \%$ have intrusive thoughts and $26 \%$ have partially or completely lost memories of the traumatic situation (characteristic signs of anxiety or neurotic disorders).

- $41 \%$ present traumatic scene-induced sleep disorders (52\%), nightmares (32\%), and idiopathic insomnia (63\%), all of which evoke the manifestations of post-traumatic stress disorder.

- $45.6 \%$ present eating disorders with predominance of anorexia.

- $50 \%$ present sexual disorders (impotence, lack of sexual desire, premature ejaculation, and anorgasmia)

- $\quad 81 \%$ of consulting patients say they manage the physical injury better than psychic suffering, compared to $19 \%$ who say the opposite and 33\% who say they have difficulty in both dimensions.

\section{Relational sphere}

- $\quad 56.5 \%$ of the wounded think society has changed their attitude towards them. While some people offer them pity, love and consider them as heroes, others take them for murderers, men "heartless".

- $74 \%$ say they have difficulty managing their family since the trauma. Indexing their absence in the family environment, conflict of ideas, change of behavior of the spouse, loss of marital and paternal authority, unjustified expenditure.

- $69 \%$ say they have serious problems with their relationship. 
- $56.5 \%$ are accused by relatives of having changed their behavior negatively (anger, lack of empathy, isolation, smoking, alcoholism).

- $74 \%$ have new projects (internship in the army 63\%, other than in the army $30 \%)$.

\section{Interpretation and Discussion}

Of the three dimensions evaluated among wounded soldiers of war, namely physical disorders, psychic disorders, and relational disorders, it turns out that the physical sphere is the dimension that poses the least difficulties ( $81 \%$ manage them better), monitoring social well-being ( $26 \%$ do not report any social problem) and psychological well-being is the last $(19 \%$ do not relate to particular psychological suffering).

\section{Clinically (psychological diagnosis)}

- Most of those injured with more than 12 months of hospitalization (73.9\%) have mood disorders and depressive symptoms (irritability, depressed mood, angry temperament), which vary from moderate to severe intensity, but unfortunately, do not make a request for consultation. These symptoms are discovered during rounds, during clinical interviews, or by some attending physicians. Most of these patients recognize the negative consequences of their behavior on those around them and their families.

- Post-traumatic stress disorder (PTSD) and generalized anxiety disorder (found in more than $50 \%$ of the wounded) are found in both the long-term and the short-term inpatients population are the nightmares, the reviviscences of the traumatic scenes, and the insomnia which are the main reasons for consultation. Unlike mood disorders and depressive disorders, patients with anxiety disorders make the consultation request by themselves, in most cases. Many of these wounded believe that there is a mystical component to their suffering.

\section{Drug addiction}

These are the wounded who misuse psychoactive substances (about 47\%). Nicotine is in the foreground, followed by THC (cannabis), then tablet containing Tramadol.

- Phantom limb and phantom pain syndromes occur in approximately $46 \%$ of amputees. They are characterized by the fact that an amputated patient, for example the right foot, continues to want to function as if this member was in place, and phantom pain is the fact for a patient for example to complain of tingling or pain located in a part of his body that was heaped on him.
- $74 \%$ of the wounded claim to have difficulty managing their family, difficulties related to their unstable mood and their disturbing behavior.

From this evaluation, it appears that relational disorders and depressive disorders are at the forefront of hospitalized soldiers (74\% and $73.9 \%$ ). These disorders predominate in those who have had more than 12 months of hospitalization. This would be justified by the fact that after several months of hospitalization, these patients would be in the phase of exhaustion from the point of view of the model of the general syndrome of adaptation, model described by Selye in $1974^{[8]}$. Anxiety disorders are in the second plan, represented mainly by PTSD and generalized anxiety found in $50 \%$ of the wounded. The fact that most of the wounded with these two disorders are less than 8 months of hospitalization is justified by the fact that they are in the phase of resistance still according to the general syndrome of adaptation. The drug addiction that comes in third position would be the consequence of the establishment of a faulty release mechanism (here the taking of a psychostimulant) to fight against the anguish of the forehead, felt before, during, and after the operations. These results show that the psychiatric disorders presented by the elements of the Cameroonian defense forces are the same as those presented by the elements of the Canadian and French defense forces. What changes, are the representations that some wounded have of the source of their injury because, about $25 \%$ of the wounded believe that there is a mystical component in the occurrence of their injury, and resort to traditional medicines and therapies religious. This is consistent with the work of Sow [9,10], and De Rosny [11], who conclude that in Africa, any illness is perceived as an expression of mystical persecution.

From previous analyzes, it appears that almost all the wounded soldiers of war, in medical evacuation at the military hospital of Yaoundé, met the psychologist and the psychiatrist for the first time. This is due to the absence of clinical and psychiatric psychologists in the health structures and intervention units of the Cameroonian armed forces. This absence would explain the high proportions of mental suffering and mental disorders presented by these results. Several factors justify these figures. Factors such as:

- The absence of psychological evaluations at the time of this study, when recruiting new elements in the Cameroonian defense forces. On the one hand, these assessments would make it possible to identify candidates with a fragile psychological profile, or those who already have mental disorders; On the other hand, they would allow the orientation of the recruits in intervention bodies adapted to their personality profile, or to facilitate the reform of the military. 
- The absence of clinical psychologists in the accompaniment of the soldier. This absence results in the absence of the psychological briefing of the soldier before his departure on mission (psychological briefing different from the military briefing), the absence of psychologists in the troops and battalions of intervention, and especially, the absence of the psychological debriefing of the soldier, on his return from the mission. Debriefing is, so far, the best technique for preventing post-traumatic stress disorder and other psychopathologies in military psychiatry [12-14].The follow-up before, during and after the intervention allows the soldier to revitalize himself psychologically, to reduce the intensity and the duration of the stress, and especially, to free himself from the emotions and negative tensions that he would have accumulated during the tests.

- The absence of psychologists and psychiatrists in the health structures of the army at this moment. This slows the speed of intervention. A soldier, survivor of an explosion in the Far North of the country, receives first aid in Maroua (north of Cameroon). This care is limited to physical injury in most cases. The absence of psychiatric symptoms during these first moments, makes believe that the soldier is without psychic injury, however, in most cases, the soldier is in a phase of resistance of the general syndrome of adaptation [8]. It is generally when the mental disorder declares that the soldier is evacuated on Yaoundé. In other cases, the soldier's complaints are not taken into consideration by the managers, who think about the simulation (even if it is the case for some). From then on, the patient arrives on Yaoundé several weeks, even several months, after the beginning of the disorder. Yet, if each military hospital had these specialists, it would facilitate early care, reduce relapses, and increase the effectiveness of primary prevention.

\section{Conclusion}

The results of this research show that physical injuries remain the most prevalent among those injured in hospital, probably because physical injuries are the main reason for medical evacuation. They are followed by mental disorders which, according to the participants, are the most difficult to overcome since they induce relational disorders which are in third and last position in the study. These mental injuries are, in order of predominance, mood disorders (73.9\%) and behavioral and mental disorders (63\%). These studies make it possible to understand once again that anxiety and depressive disorders remain the most frequent among mental illnesses, as American Psychiatric Association (APA) [15] points out. The predominance of depressive disorders among these elements of the defense force after a long period of hospitalization would simply translate the tilting of the organism into a depressive physiology, after a long period of resistance to anxiety. Post-traumatic stress disorder, the primary anxiety disorder presented by soldiers, is gradually turning into a mood disorder, primarily a depressive disorder. The data from this research shows that it is time for decision-makers or administrators of the Cameroonian army to consider something other than what has hitherto been set up as a system for the care of these war-wounded. Not only must psychological monitoring be done upstream before deployment to the front, but also be intensified after returning from the front when taking care of physical injuries, and above all must be more specific and specific after discharge from hospital when they return to their families or to their unit.

\section{Acknowledgements}

We thank the head doctor of the hospital, colonel-doctor Jacba, for allowing us to collect this data.

\section{Conflict of Interest}

No conflict of interest.

\section{Bibliography}

1. Mondji L. "Le différend frontalier Cameroun-Nigeria dans la zone du lac Tchad avec accent sur Darak (dimension historique)". In Rapport de recherche présenté dans le cadre de l'UV HS 304, Sensibilisation à la recherche en Histoire (université de N'Gaoundéré) (2004).

2. Briole G., et al. "Psychiatrie militaire en situation opérationnelles". Paris: Eddim (1998).

3. Campeano M. "Essai de psychologie militaire”. Paris: Maloine (1902).

4. Gagné L. “Détresse des militaires”. Santé mentale 11.5 (2014): 32-34.

5. Zamorski MA., et al. "Prevalence and correlates of mental health problems in Canadian Forces personnel who deployed in support of the mission in Afghanistan: findings from postdeployment screenings, 2009-2012". Canadian Journal of Psychiatry 59.6 (2014): 319-326. 
6. Boulos D and Zamorski MA. “Deployment-related mental disorders among Canadian Forces personnel deployed in support of the mission in Afghanistan, 2001-2008". Canadian Medical Association Journal 185.11 (2013): 545-552.

7. Galbert V-P. "Vivre avec une victime d'attentat, le traumatisme des proches". Paris: Odile Jacob (2018).

8. Maniguet X. "Bien vivre avec son stress". Paris: De Vecchi (2009).

9. Sow AI. "Psychiatrie dynamique Africaine". Paris: Payot (1977).

10. Sow AI. "Structure anthropologique de la folie en Afrique Noire". Paris: Payot (1978).

11. De Rosny E. “Afrique des guérisons”. Paris: Karthala (1992).

12. Courtine S. "Le débriefing, retour sur l'expérience". Paris: Ce$\operatorname{dex}(2005)$.

13. De Soir E and Vermeiren E. "Le débriefing psychologique en question". Antwerpen-Apeldoorn: Garant (2002).

14. Thomas G. "Le débriefing psychologique". Neuropsy News 2.1 (2003): 87-91.

15. American Psychiatric Association [APA] "DSM-V: manuel diagnostique et statistique des troubles mentaux (5e éd.) (MA. Crocq and J.-D. Guelfi, coord. trad.). Paris: Elsevier Masson (2013).

\section{Assets from publication with us}

- Prompt Acknowledgement after receiving the article

- Thorough Double blinded peer review

- Rapid Publication

- Issue of Publication Certificate

- High visibility of your Published work

Website: https://www.actascientific.com/

Submit Article: https://www.actascientific.com/submission.php Email us: editor@actascientific.com

Contact us: +919182824667 